Article

\title{
Enhanced Cycle Stability of Zinc Sulfide Anode for High-Performance Lithium-Ion Storage: Effect of Conductive Hybrid Matrix on Active ZnS
}

\author{
Quoc Hanh Nguyen, Taehyun Park and Jaehyun Hur*D \\ Department of Chemical and Biological Engineering, Gachon University, Seongnam-si, \\ Gyeonggi-do 13120, Korea \\ * Correspondence: jhhur@gachon.ac.kr; Tel.: +82-10-9370-3596
}

Received: 9 August 2019; Accepted: 27 August 2019; Published: 29 August 2019

check for updates

\begin{abstract}
Zinc sulfide ( $\mathrm{ZnS}$ ) nanocrystallites embedded in a conductive hybrid matrix of titanium carbide and carbon, are successfully fabricated via a facile high-energy ball-milling (HEBM) process. The structural and morphological analyses of the ZnS-TiC-C nanocomposites reveal that $\mathrm{ZnS}$ and TiC nanocrystallites are homogeneously distributed in an amorphous carbon matrix. Compared with ZnS-C and ZnS composites, the ZnS-TiC-C nanocomposite exhibits significantly improved electrochemical performance, delivering a highly reversible specific capacity $\left(613 \mathrm{~mA} \mathrm{~h} \mathrm{~g}^{-1}\right.$ over 600 cycles at $0.1 \mathrm{~A} \mathrm{~g}^{-1}$, i.e., $~ 85 \%$ capacity retention), excellent long-term cyclic performance (545 $\mathrm{mA} \mathrm{h} \mathrm{g}^{-1}$ and $467 \mathrm{~mA} \mathrm{~h} \mathrm{~g}^{-1}$ at $0.5 \mathrm{~A} \mathrm{~g}^{-1}$ and $1 \mathrm{~A} \mathrm{~g}^{-1}$, respectively, after 600 cycles), and good rate capability at $10 \mathrm{~A} \mathrm{~g}^{-1}\left(69 \%\right.$ capacity retention at $\left.0.1 \mathrm{~A} \mathrm{~g}^{-1}\right)$. The electrochemical performance is significantly improved, primarily owing to the presence of conductive hybrid matrix of titanium carbide and amorphous carbon in the ZnS-TiC-C nanocomposites. The matrix not only provides high conductivity but also acts as a mechanical buffering matrix preventing huge volume changes during prolonged cycling. The lithiation/delithiation mechanisms of the $\mathrm{ZnS}-\mathrm{TiC}-\mathrm{C}$ electrodes are examined via ex situ X-ray diffraction (XRD) analysis. Furthermore, to investigate the practical application of the $\mathrm{ZnS}-\mathrm{TiC}-\mathrm{C}$ nanocomposite, a coin-type full cell consisting of a ZnS-TiC-C anode and a $\mathrm{LiFePO}_{4}-$ graphite cathode is assembled and characterized. The cell exhibits excellent cyclic stability up to 200 cycles and a good rate performance. This study clearly demonstrates that the ZnS-TiC-C nanocomposite can be a promising negative electrode material for the next-generation lithium-ion batteries.
\end{abstract}

Keywords: zinc sulfide; titanium carbide; anode; high-energy ball milling; Li-ion batteries

\section{Introduction}

Rechargeable Li-ion batteries (LIBs) have been widely used for mobile portable electronic devices and electric vehicles, owing to their high energy densities, long lifecycles, and low self-discharge rates [1-3]. The rapidly increasing demand for electric vehicles and portable devices necessitates new alternative electrode materials with higher capacities, higher energy densities, and good safety. Currently, the most commonly used anode for LIBs is graphite, but it is unable to satisfy the demands of high energy and power densities, owing to its poor rate capacity, low tap density $\left(<1 \mathrm{~g} \mathrm{~cm}^{-3}\right)$, and critical safety concerns related to Li plating [4-6]. Hence, enormous efforts have been devoted to the development of high-performance anodes with high capacity and enhanced safety characteristics [7-10]. To satisfy these requirements, numerous Li-alloying anodes have been proposed as potential candidates for replacing graphite, including Li-Sn, Li-Si, Li-Sb, Li-P, and Li-Ge [11-16].

Metallic $\mathrm{Zn}$ is one of the promising alternative anodes for rechargeable LIBs owing to its high theoretical volumetric capacity $\left(1511 \mathrm{~mA} \mathrm{~h} \mathrm{~cm}^{-3}\right)$ and it can easily form various Zn-metal 
binary alloying compounds, such as Zn-Sb, Zn-P, Zn-Se, Zn-Te, and Zn-S, among others [17-25]. Additionally, its beneficial features including natural abundance, inexpensiveness, and environmental friendliness suggest $\mathrm{Zn}$ as a promising material for LIB anodes. Despite these merits, Zn-based anodes inevitably undergo large volume expansion (about $70 \%$ and $228 \%$ for $\mathrm{Zn}$ and $\mathrm{ZnO}$ anodes, respectively) [26,27] during Li alloying/dealloying, resulting in the particle pulverization of active particles upon extended electrochemical cycling, which lead to poor cycling performance, similar to other Li-alloying materials [12,16]. In this regard, the introduction of a conductive TiC-C hybrid matrix composed of titanium carbide (TiC) and amorphous $\mathrm{C}$, which can serve as an efficient buffering matrix that improves the cyclic stability and rate capability, has been proved as a promising candidate for satisfying these requirements [28-35]. TiC can effectively suppress the internal stress and prevent the agglomeration of active particles upon extended cycling, owing to its good mechanical properties and electrochemical stability $[36,37]$. Moreover, the synergistic effect between titanium carbide and amorphous carbon in the conductive $\mathrm{TiC}-\mathrm{C}$ hybrid matrix not only provides the high electrical conductivity but also mitigates particle aggregation, improving the electrochemical performance [33].

Another effective strategy for solving these problems is to create a metallic chalcogenide compound that can progressively react with Li-ions during cycling. In this respect, $\mathrm{S}$ is one of the potential candidates for LIB anodes owing to its cheapness, natural abundance, eco-friendliness, and very high theoretical specific capacity $\left(1675 \mathrm{~mA} \mathrm{~h} \mathrm{~g}^{-1}\right)$, which is much higher than other chalcogens (e.g., Se $\left(678 \mathrm{~mA} \mathrm{~h} \mathrm{~g}^{-1}\right)$ and $\left.\mathrm{Te}\left(420 \mathrm{~mA} \mathrm{~h} \mathrm{~g}^{-1}\right)\right)$ [38-41]. Unfortunately, the application of the standalone S-based electrode is impractical because of its low electronic conductivity $\left(\sim 5 \times 10^{-22} \mathrm{~S} \mathrm{~cm}^{-1}\right)$, the dissolution of Li polysulfides, and the large volume expansion upon extended cycling. Therefore, many ZnS-based composites have been reported as high-performance anode materials owing to their very high theoretical specific capacities $\left(829 \mathrm{~mA} \mathrm{~h} \mathrm{~g}^{-1}\right)$, but their electrochemical performance remains unsatisfactory, as shown in Table S1 [42-49]. Moreover, the lithiation/delithiation potential of an active $\mathrm{ZnS}$ anode is much higher than the reaction potential of metallic $\mathrm{Li}$, preventing the safety concerns associated with Li plating, which eventually results in dendrite growth and short circuiting [50,51].

Herein, we report an effective strategy to obtain improved electrochemical performance of a ZnS-based nanocomposite, by introducing $\mathrm{ZnS}$ nanoparticles into an efficient matrix of $\mathrm{TiC}$ and amorphous $\mathrm{C}$ via a facile and scalable high-energy ball-milling (HEBM) process. The ZnS-TiC-C nanocomposite has the following advantages as a new anode for LIBs. (i) The reaction between $\mathrm{Zn}$ and $\mathrm{S}$ forms an II-VI ZnS compound, which mitigates the large volume expansion due to the progressive electrochemical reactions and contributes to a high capacity. (ii) The TiC and C hybrid matrix acts as a buffering matrix that can prevent particle agglomeration and suppress the high volume change of active $\mathrm{ZnS}$ particles during cycling. (iii) The high conductivity of the TiC-C hybrid matrix provides facile electron transport, thereby contributing to the excellent electrochemical performance of the ZnS-TiC-C electrodes. We demonstrate the practical application of the ZnS-TiC-C nanocomposite as a high-performance anode material in a full-cell investigation.

\section{Materials and Methods}

\subsection{Material Preparation}

The ZnS-TiC-C nanocomposites were synthesized through a facile HEBM process using a planetary ball milling (Pulverisette 5, Fritsch) machine. First, a mixture of zinc $(\geq 98 \%,<10 \mu \mathrm{m}$, Sigma-Aldrich, St. Louis, MO, USA), sulfur (99.998\%, trace metal basis, Sigma-Aldrich), and titanium $(99.99 \%, 325$ mesh, Alfa Aesar, MA, USA) powders was manually ground and then placed into a hardened zirconium oxide bowl $\left(80 \mathrm{~cm}^{3}\right)$ with hardened zirconium oxide balls (with different sizes of $3 / 8$ and 3/16 inches) and tightly closed in a glovebox under an Ar atmosphere. The mass ratio of $\mathrm{ZrO}_{2}$ balls to powder was 20:1 and the total weight of mixing powders was $2.0 \mathrm{~g}$. The first HEBM process was carried out at a rotation speed of $300 \mathrm{rpm}$ at ambient temperature for $10 \mathrm{~h}$. The resulting mixture was mixed and manually ground with an appropriate amount of acetylene carbon black powder $(100 \%$ compressed, 
99.9\%, Alfa Aesar). The second HEBM process was then operated under the identical conditions that were applied in the first process, in order to form the conductive $\mathrm{TiC}$ phase in the resulting composites. For comparison, the same procedure was applied without Ti at the initial mixing stage to form ZnS-C with a ZnS:C weight ratio of 8:2. Another control sample of a $\mathrm{ZnS}$ composite was prepared similarly without Ti and $\mathrm{C}$. Additionally, we determined the optimum content of the active material ( $\mathrm{ZnS}$ ) by changing the weight percentage of $\mathrm{ZnS}$ (from $60 \%$ to $90 \%$ ), along with the corresponding amounts of $\mathrm{Ti}$ and amorphous $\mathrm{C}$, such that the mass ratio of TiC: $\mathrm{C}$ was fixed at 1:2. These samples were denoted as ZnS(60\%)-TiC-C, ZnS(70\%)-TiC-C, ZnS(80\%)-TiC-C, and ZnS(90\%)-TiC-C.

\subsection{Material Characterization}

The crystal structures of the ZnS-based composites were analyzed with an X-ray diffractometer with $\mathrm{Cu} \mathrm{K} \alpha$ radiation $(\lambda=0.15406 \mathrm{~nm})$ in a $2 \theta$ range of $20-80^{\circ}$ at a scan rate of $2^{\circ} \mathrm{min}^{-1}$ (XRD, D/MAX-2200 Rigaku, Japan, at the Smart Materials Research Center for IoT (internet of things) at Gachon University for its instrumental support). The ex-situ XRD measurements were conducted at three states (pristine, fully discharged, and fully charged) to investigate the reaction mechanism of the ZnS-TiC-C electrode. The electrochemical coin-type cells were disassembled using wolf looping pliers in a glove box and rinsed with anhydrous dimethyl carbonate. These dismantled electrodes were then dried and covered with a layer of Kapton film to prevent direct contact with air. Scanning electron microscopy (SEM, Hitachi S4700, Tokyo, Japan), high resolution transmission electron microscopy (HRTEM, TECNAI G2F30, FEI corp., OR, USA), and scanning transmission electron microscopy (STEM, TECNAI G2F30, FEI corp., OR, USA) with energy dispersive X-ray spectroscopy (EDS) were conducted to investigate the morphologies, compositions, and elemental distributions of the as-prepared samples. The morphologies of the ZnS-TiC-C and ZnS-C electrodes after 50 cycles were observed by ex-situ SEM analysis.

\subsection{Electrochemical Measurements}

To investigate the electrochemical performances, the working anodes were prepared by coating the slurries containing $70 \mathrm{wt} \%$ of active materials (the as-synthesized ZnS-TiC-C, ZnS-C, and ZnS), $15 \mathrm{wt} \%$ of conductive carbon black (Super P), and $15 \mathrm{wt} \%$ binder of polyvinylidene fluoride (PVDF) dissolved in $\mathrm{N}$-methyl-pyrrolidone (NMP) solvent. The slurry coating onto $\mathrm{Cu}$ foils was performed by doctor blading, followed by drying at $70{ }^{\circ} \mathrm{C}$ overnight under vacuum. The dried electrodes were cut in the shape of circular discs with a diameter of $12 \mathrm{~mm}$. The working electrodes were used as anodes for CR2032-type coin cells and assembled in an Ar-filled glovebox to avoid $\mathrm{O}_{2}$ and moisture. Metallic Li foil, $1 \mathrm{M} \mathrm{LiPF}_{6}$ dissolved in diethyl carbonate/ethylene carbonate ( $1: 1$ by $\left.v / v\right)$, and polyethylene were used as the counter electrode, electrolyte solution, and separator, respectively. The mass loadings of active materials and the electrodes were typically $\sim 0.8 \mathrm{mg}$ and $\sim 1.2 \mathrm{mg}$, respectively. The volume of liquid electrolyte loaded in the cell was $\sim 0.2 \mathrm{~mL}$. Galvanostatic charge/discharge experiments were conducted at a constant current density of $0.1 \mathrm{~A} \mathrm{~g}^{-1}\left(\sim 1 / 6 \mathrm{C}\right.$-rate) within the potential range $0.01-2.5 \mathrm{~V}\left(\mathrm{vs} . \mathrm{Li} / \mathrm{Li}^{+}\right)$ using a battery cycler (WBCS3000, WonATech, Seoul, South Korea). The cyclic voltammogram (CV) was measured using a ZIVE MP1 (WonATech) instrument in the same potential range, at the scan rate of $0.1 \mathrm{mV} \mathrm{s}^{-1}$. The rate capabilities were measured at various current densities ranging from $0.1-10 \mathrm{~A} \mathrm{~g}^{-1}$ using a WBCS3000 (WonATech) battery cycler. A ZIVE MP1 (WonATech) analyzer was used for electrochemical impedance spectroscopy (EIS) measurements in the range of $100 \mathrm{kHz}-100 \mathrm{mHz}$ with a $10-\mathrm{mV}$ alternating-current amplitude. For a full-cell investigation, as-prepared $\mathrm{ZnS}(80 \%)-\mathrm{TiC}-\mathrm{C}$ and $\mathrm{LiFePO}_{4}$-graphite (denoted as LFP-G) electrodes were used as an anode and cathode, respectively. The electrolyte, separator, and coin cell for the full cell were the same as those used in the half-cell. The LFP-G cathode was synthesized by mixing $\mathrm{LiFePO}_{4}(<5 \mu \mathrm{m},>97 \%$, Sigma-Aldrich, St. Louis, MO, USA) and graphite (200 mesh, $99.9999 \%$, Alfa Aesar) powders at a mass ratio of 7:3. The resulting mixture was ball-milled for $10 \mathrm{~h}$ at a rotation speed of $300 \mathrm{rpm}$ in an Ar atmosphere. The slurry for the cathode material was prepared by mixing LFP-G $(80 \%)$, Super P (10\%), and PVDF (10\%) dissolved in an 
NMP solvent. Then, the cathode slurry was coated onto an $\mathrm{Al}$ foil and dried at $70{ }^{\circ} \mathrm{C}$ overnight under vacuum. For testing the electrochemical performance of the full cell, CR2032 coin cells containing the cathode and anode were electrochemically pre-charged and pre-discharged to make the batteries more stable by removing the effects of solid-electrolyte interphase (SEI) layer formation. Then, these test cells were assembled in a glovebox. Galvanostatic cycling and rate capability tests were performed within the voltage range of 1.0-3.8 V using a battery cycler (WBCS3000, WonATech). The total capacity of the full cell was calculated according to the total mass of active cathode and anode materials, the mass ratio of the cathode to the anode was $\sim 2: 1$.

\section{Results and Discussion}

The crystalline structures of the ZnS-TiC-C, ZnS-C, and ZnS composites were characterized via XRD analysis (Figure 1a). All the XRD patterns of the as-prepared samples exhibited a series of peaks at $\sim 29^{\circ}, 33^{\circ}, 47^{\circ}, 56^{\circ}$, and $77^{\circ}$, which are designated to the (111), (200), (220), (311), and (331) planes of the cubic ZnS crystalline phase (PDF\#05-0566), indicating the successful synthesis of ZnS. For the ZnS-TiC-C composite, two additional XRD peaks were observed at $\sim 39^{\circ}$ and $\sim 56^{\circ}$, corresponding to the crystalline structure of the TiC phase (PDF\#74-1219), confirming the conductive TiC phase formation after the two-step HEBM. The presence of the conductive TiC phase in the composite after the HEBM agrees well with previous reports [29,32,34,35]. Compared with the ZnS and ZnS-C composites, the ZnS-TiC-C nanocomposite exhibited broader ZnS peaks with lower intensities, suggesting the size reduction of the $\mathrm{ZnS}$ crystallites in the $\mathrm{ZnS}-\mathrm{TiC}-\mathrm{C}$, which is ascribed to the fracturing and deformation of ZnS particles, caused by contact with the mechanically strong TiC phase during the HEBM [36,37]. Although pure $\mathrm{Zn}, \mathrm{Ti}$, and $\mathrm{S}$ peaks were observed after the first HEBM step (as shown in Figure 1b), the mixture was completely converted into alloy phases, including $\mathrm{ZnS}$, $\mathrm{TiC}$, and amorphous $\mathrm{C}$, after the second HEBM step (Figure 1a). No additional peaks were detected, suggesting there are no impurities in the final product and that the $\mathrm{Zn}, \mathrm{S}, \mathrm{Ti}$, and $\mathrm{C}$ were completely transformed into $\mathrm{ZnS}$ and TiC crystallites and amorphous $C$ after the two-step ball-milling process. A schematic of the overall synthesis of the ZnS-TiC-C nanocomposite is presented in Figure 1c. The metastable Zn-S-Ti alloy was formed after the first HEBM process, followed by the formation of a ZnS-TiC-C composite when amorphous $\mathrm{C}$ was added to the $\mathrm{Zn}$-S-Ti mixture upon the second HEBM process. The overall reaction for the synthesis of the $\mathrm{ZnS}-\mathrm{TiC}-\mathrm{C}$ nanocomposite is expressed as follows:

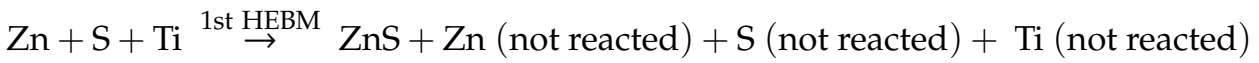

$$
\begin{aligned}
& \text { 2nd HEBM } \\
& \stackrel{(+ \text { carbon black })}{\longrightarrow} \mathrm{ZnS}-\mathrm{TiC}-\mathrm{C}
\end{aligned}
$$



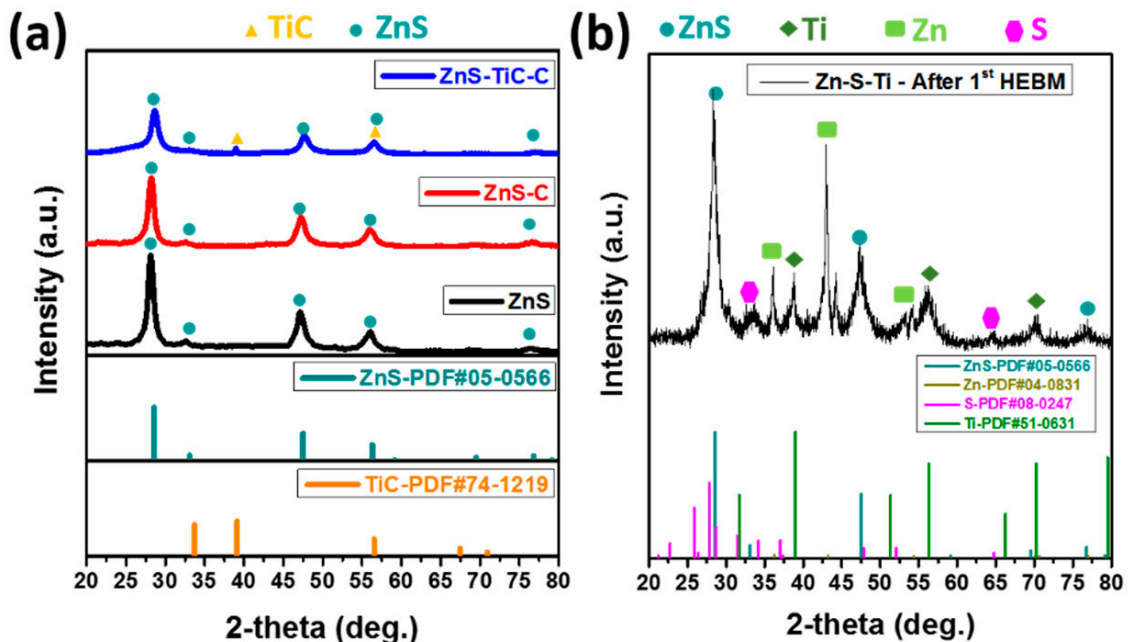

(c)

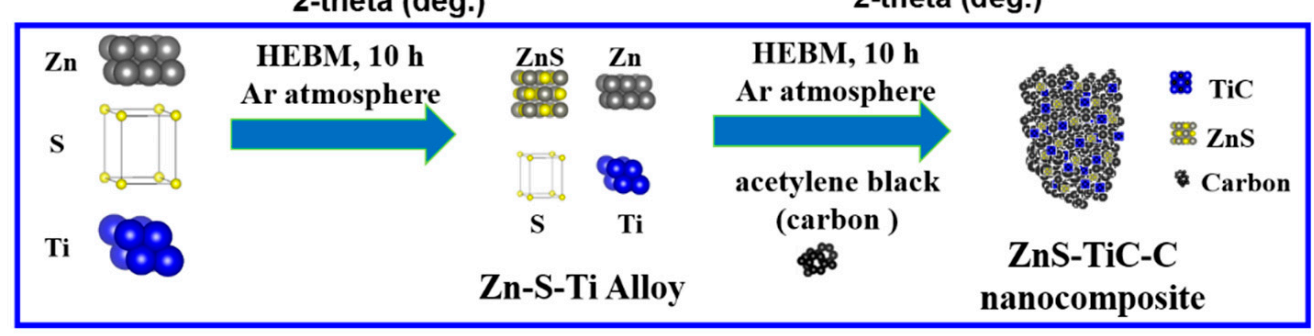

Figure 1. XRD patterns for (a) the ZnS, ZnS-C, and ZnS-TiC-C composites, (b) the Zn-S-Ti alloy after the first high-energy ball-milling (HEBM) process; and (c) schematic of the synthesis of the ZnS-TiC-C composite.

Figure 2 shows the microscopic morphologies and particle-size distributions of the ZnS-TiC-C, $\mathrm{ZnS}-\mathrm{C}$, and ZnS composites. As indicated by the SEM images (Figure $2 \mathrm{a}-\mathrm{c}$ ), the average particle size for all the samples ranged from a few micrometers to hundreds of nanometers. Compared with the ZnS-C and $\mathrm{ZnS}$, the ZnS-TiC-C nanocomposite had a larger percentage of particles with a size of $<100 \mathrm{~nm}$ (up to $90 \%$, as shown in Figure 2d). The remarkable decrease in the average particle size of the ZnS-TiC-C composite confirmed the continuous fracturing of $\mathrm{ZnS}$ particles with the hard and strong $\mathrm{TiC}$ phase during the HEBM process [29,32].
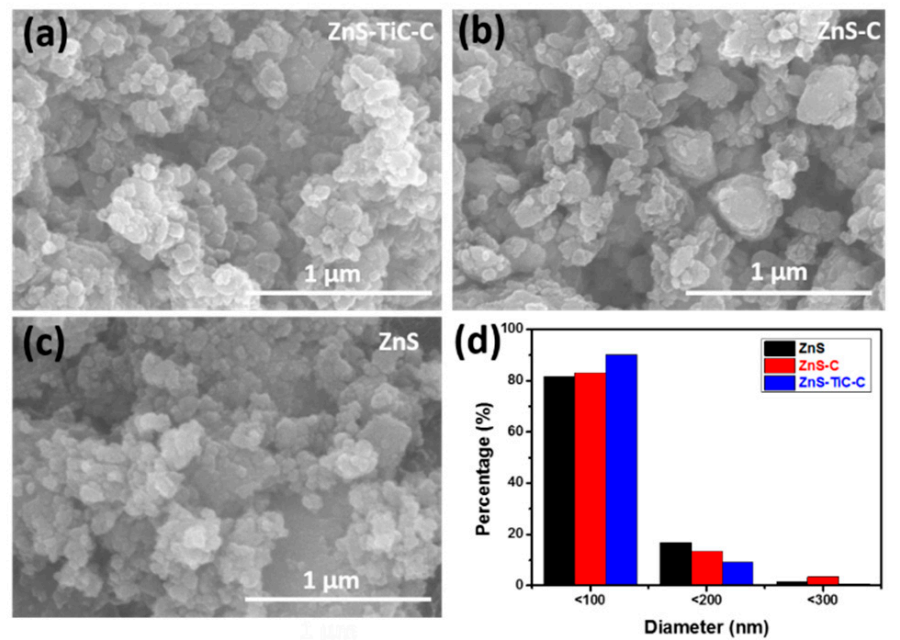

Figure 2. SEM images of the (a) ZnS-TiC-C, (b) ZnS-C, (c) ZnS composites; and (d) particle-size distributions of the ZnS, ZnS-C, and ZnS-TiC-C composites. 
The morphology and elemental distribution of the ZnS-TiC-C nanocomposite were analyzed via transmission electron microscopy (TEM), HRTEM, and STEM, together with EDS mapping (Figure 3). The low- and high-resolution TEM images shown in Figure 3a-c reveal the detailed microstructure of the ZnS-TiC-C nanocomposite. The ZnS and TiC nanocrystallites (darker areas of 5-10 nm) were embedded in an amorphous $C$ matrix (brighter areas). The high-resolution TEM images presented in Figures $3 b$ and $3 c$ exhibited two different interplanar spacings $(0.312$ and $0.162 \mathrm{~nm})$, corresponding to the (111) plane of crystalline $\mathrm{ZnS}$ and the (200) plane of crystalline $\mathrm{TiC}$, respectively, in agreement with the XRD results in Figure 1a. Using the selected-area electron diffraction patterns (inset in Figure 3c), the presence of crystalline ZnS (111) and TiC (200) was confirmed, by indexing the interplanar distance and lattice plane. Furthermore, the STEM images and EDS elemental mapping revealed that there was a uniform distribution of nanosized $\mathrm{ZnS}$ and $\mathrm{TiC}$ throughout the carbon matrix. The results confirmed the small amount of $\mathrm{Ti}(5.33 \mathrm{wt} \%$ ) in the $\mathrm{ZnS}-\mathrm{TiC}-\mathrm{C}$ nanocomposite (Figure $3 \mathrm{~d}$ ). The powder morphology is considered to be advantageous for the anode material in LIBs because of the strong buffering effect of the well-mixed TiC-C hybrid matrix against large volume expansions, as well as the enhanced conductivity in the nanocomposite.
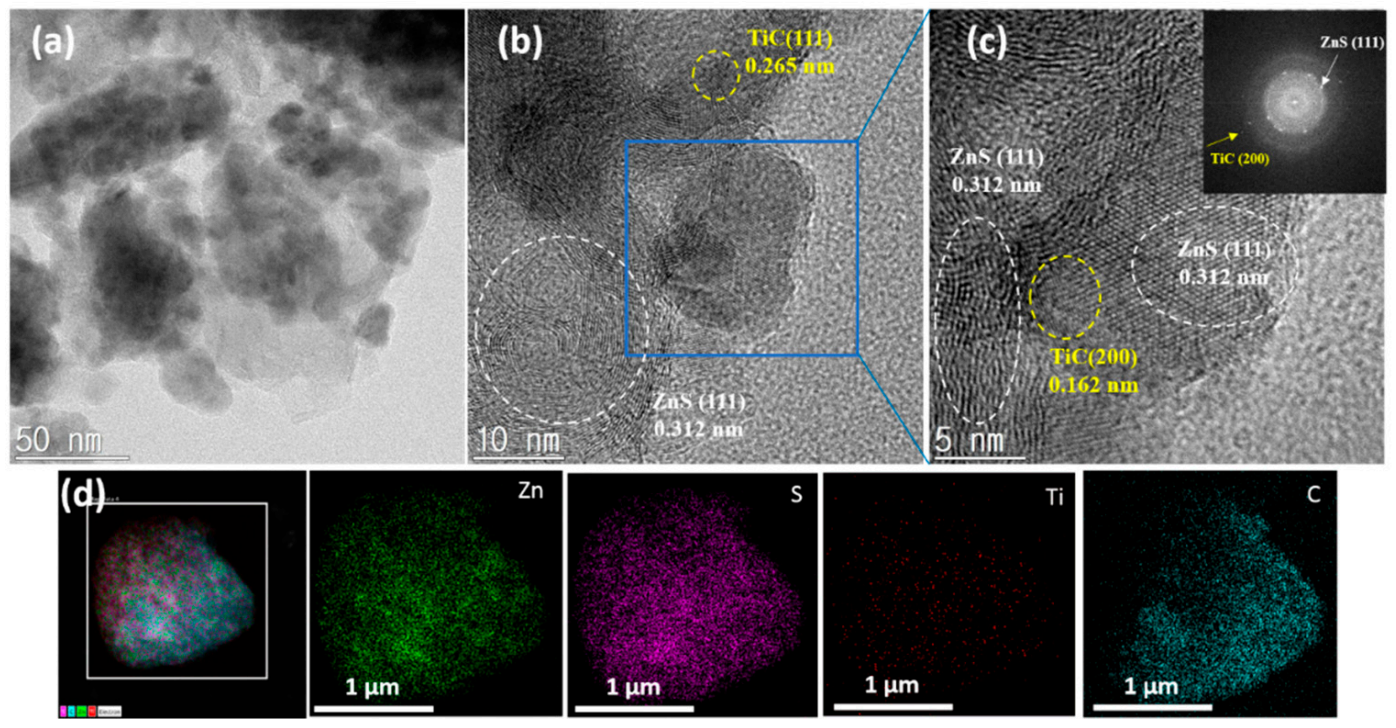

Figure 3. $(\mathbf{a}-\mathbf{c})$ TEM and HRTEM images of the ZnS-TiC-C composite; and (d) STEM image with EDS mapping images of the $\mathrm{ZnS}-\mathrm{TiC}-\mathrm{C}$ composite.

Galvanostatic charge/discharge measurements were conducted at $0.1 \mathrm{~A} \mathrm{~g}^{-1}$ over the range of 0.01-2.5 V (vs. $\mathrm{Li} / \mathrm{Li}^{+}$). Figure 4 a presents the initial charge/discharge profiles of the ZnS, ZnS-C, and ZnS-TiC-C electrodes. The ZnS and ZnS-C electrodes delivered initial discharge/charge capacities of 1014/609 and 859/501 $\mathrm{mA} \mathrm{h} \mathrm{g}^{-1} / \mathrm{mA} \mathrm{h} \mathrm{g}^{-1}$, respectively, corresponding to low initial coulombic efficiencies (ICEs) of $\sim 60 \%$ and $\sim 58 \%$, respectively. In comparison, the ZnS-TiC-C electrode exhibited a higher ICE ( 66\%), as evidenced by the initial discharge and charge capacities of 903 and $594 \mathrm{~mA} \mathrm{~g}$ $\mathrm{h}^{-1}$, respectively. The initial capacity loss was primarily caused by the irreversible reaction of active $\mathrm{ZnS}$ with $\mathrm{Li}^{+}$ions, and the SEI layer formed on the electrode surface [29,32]. Thus, the ZnS-TiC-C nanocomposite was expected to improve the reversibility of the electrode, because the introduction of the TiC-C phase significantly suppressed the volume change of the active ZnS particles, enhancing the ICE. 

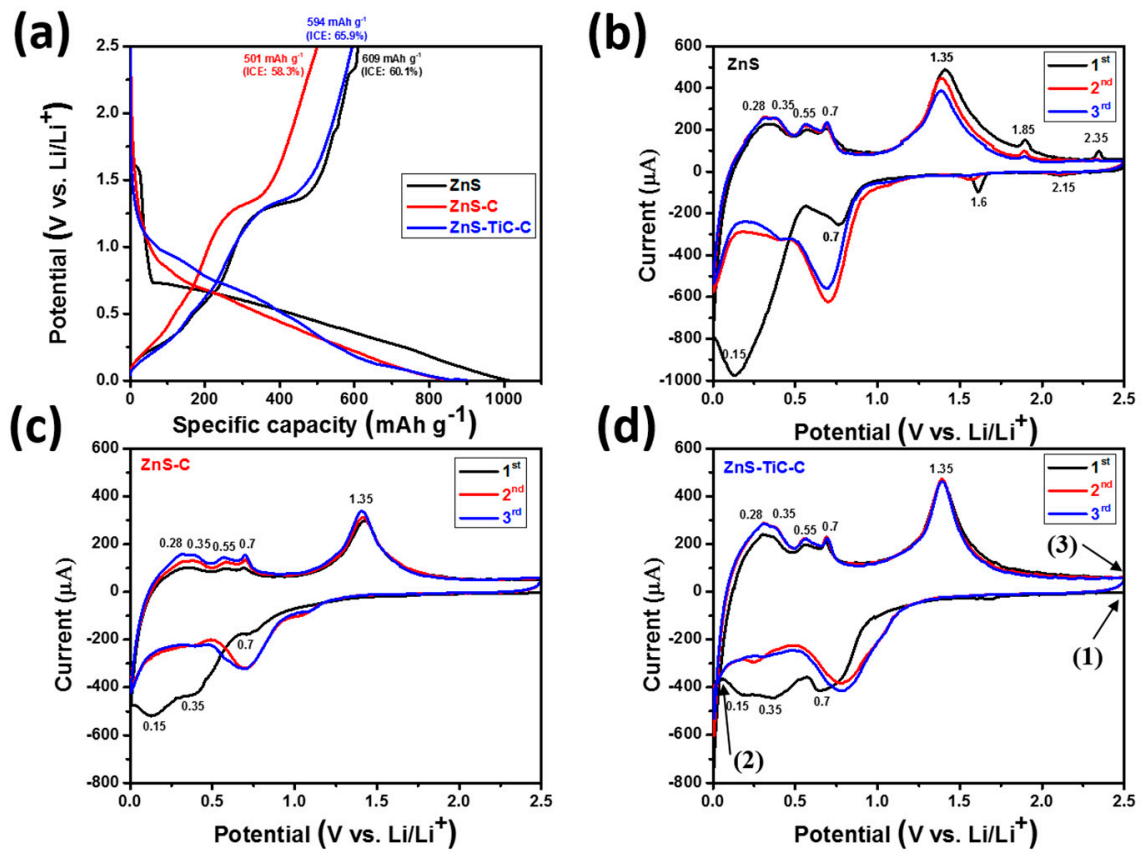

Figure 4. (a) Initial charge/discharge profiles and (b-d) cyclic voltammogram (CV) curves of the ZnS, ZnS-C, and ZnS-TiC-C electrodes.

Figure $4 \mathrm{~b}-\mathrm{d}$ present the $\mathrm{CV}$ curves of the ZnS, ZnSC, and ZnS-TiC-C composites for the initial three cycles, as consistent with previous reports of ZnS-based anode materials [42,43,47]. The CV curve of the $\mathrm{ZnS}$ electrode (Figure $4 \mathrm{~b}$ ) was used to investigate the electrochemical reactions between $\mathrm{ZnS}$ and Li. During the first discharge process of the $\mathrm{ZnS}$ electrode, a small cathodic peak appeared around $0.7 \mathrm{~V}$, which was related to the reduction reaction of $\mathrm{ZnS}$ to generate $\mathrm{Li}_{2} \mathrm{~S}$ and metallic $\mathrm{Zn}$. The large and broad peak in the voltage range of $0.01-0.4 \mathrm{~V}$ corresponds to the further sequential lithiation reactions of $\mathrm{Zn}$ to form various $\mathrm{Li}_{x} \mathrm{Zn}$ phases, eventually forming the $\mathrm{LiZn}$ phase $\left(\mathrm{Zn} \rightarrow \mathrm{LiZn}_{4} \rightarrow \mathrm{LiZn}\right.$ ) in the fully lithiated state $[43,44]$. The cathodic peaks are partly ascribed to the SEI layer formation on the electrode surface, which was responsible for part of the irreversible capacity. During the first charge process, four anodic peaks were detected in the voltage range of $\sim 0.3-0.7 \mathrm{~V}$, indicating the successive delithiation reactions from $\mathrm{LiZn}$ to $\mathrm{Zn}$ through several steps $\left(\mathrm{LiZn} \rightarrow \mathrm{Li}_{2} \mathrm{Zn}_{3} \rightarrow \mathrm{LiZn}_{2} \rightarrow \mathrm{LiZn}_{4} \rightarrow \mathrm{Zn}\right)$ [23,33]. The next oxidation peak was observed at $\sim 1.35 \mathrm{~V}$, corresponding to the recombination of $\mathrm{ZnS}$ from $\mathrm{Zn}$ and $\mathrm{Li}_{2} \mathrm{~S}$. The basic intercalation reaction of $\mathrm{ZnS}$ can be expressed as follows [42-44,47]:

$$
\begin{gathered}
\mathrm{ZnS}+\mathrm{Li}^{+}+\mathrm{e}^{-} \rightarrow \mathrm{Zn}+\mathrm{Li}_{2} \mathrm{~S} \\
\mathrm{Zn}+\mathrm{xLi}^{+}+\mathrm{xe}^{-} \rightarrow \mathrm{Li}_{\mathrm{x}} \mathrm{Zn}
\end{gathered}
$$

In the subsequent cycles, the reduction and oxidation peaks almost coincided with each other, suggesting the excellent reversibility of the ZnS-based electrodes. CV behaviors similar to those of the $\mathrm{ZnS}$ electrode were observed for the $\mathrm{ZnS}-\mathrm{C}$ and $\mathrm{ZnS}-\mathrm{TiC}-\mathrm{C}$ electrodes, as shown in Figure 4c, d, except for the additional two pairs of redox peaks at 1.85/1.6 V and 2.35/2.15 V, which may have resulted from the formation of a $\mathrm{ZnO}$ impurity in the case of the $\mathrm{ZnS}$ electrode [43].

To elucidate the lithiation/delithiation reaction mechanism of the ZnS-TiC-C electrode during cycling, the ex-situ XRD experiments were performed for the ZnS(80\%)-TiC-C electrode (Figure 5a). The three cutoff potentials marked in Figure $4 d$ (see arrows) correspond to the pristine, fully discharged, and charged states of $\mathrm{ZnS}-\mathrm{TiC}-\mathrm{C}$. Clearly, all the $\mathrm{ZnS}$ peaks were observed for the pristine state, in agreement with the XRD results (Figure 1a). After fully discharged to $0.01 \mathrm{~V}$, additional peaks of $\mathrm{Li}_{2} \mathrm{~S}\left(\sim 27^{\circ}\right.$ and $\left.\sim 31^{\circ}\right)$ and $\operatorname{LiZn}\left(\sim 25^{\circ}\right.$ and $\left.\sim 41^{\circ}\right)$ were observed, and the $\mathrm{ZnS}$ peaks disappeared, 
indicating that the $\mathrm{ZnS}$ phase was completely converted into $\mathrm{Li}_{2} \mathrm{~S}$ and $\mathrm{LiZn}$ phases. In contrast, at the fully charged state at $2.5 \mathrm{~V}$, all of the $\mathrm{LiZn}$ and $\mathrm{Li}_{2} \mathrm{~S}$ peaks disappeared, and the $\mathrm{ZnS}$ peaks reappeared. This result indicates the reversible lithiation/delithiation of $\mathrm{ZnS}$ and suggests that no structural changes occurred during the cycling process. The TiC peaks were not clearly observed in the ex-situ XRD results, owing to the low amplitude of the signal in the measurements, as well as the low TiC content $(6.67 \%)$ in the ZnS-TiC-C nanocomposite. A schematic of the electrochemical mechanism is presented in Figure $5 b$.
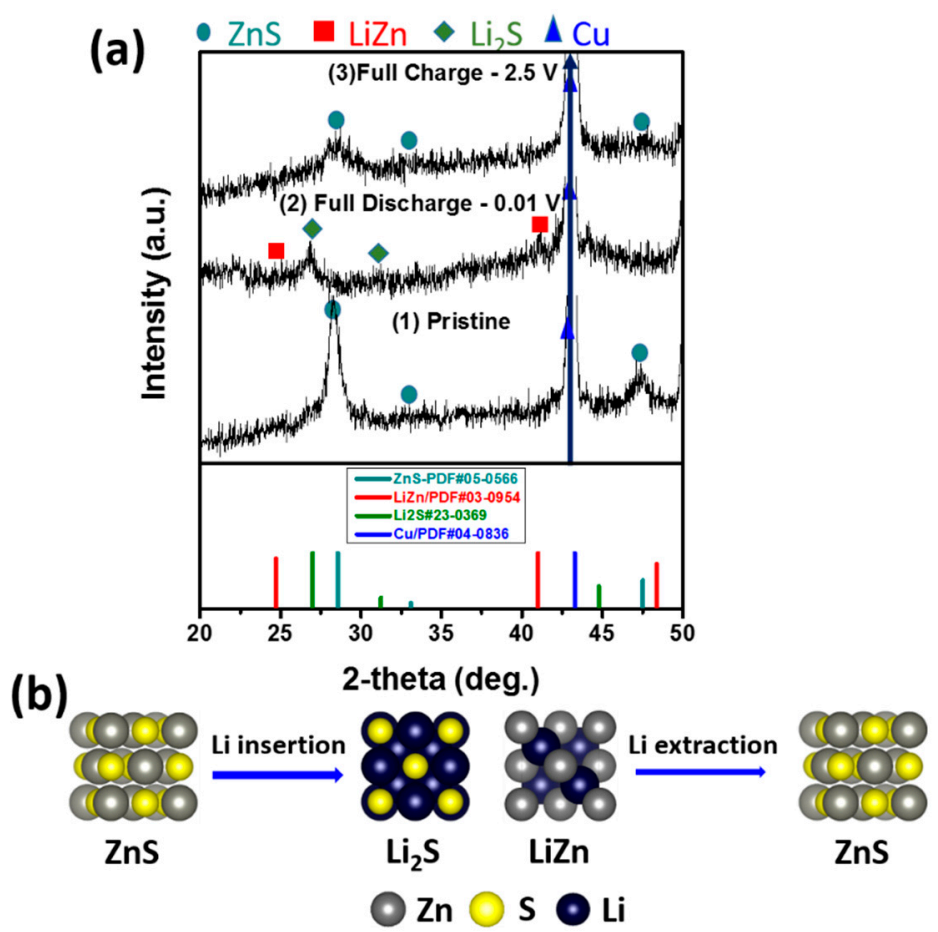

Figure 5. (a) Ex-situ XRD patterns for the ZnS-TiC-C electrode after the first charge/discharge cycle and (b) schematic of the reaction mechanism.

Figure 6a compares the cyclic performances and coulombic efficiencies (CEs) of the ZnS-based electrodes at $0.1 \mathrm{~A} \mathrm{~g}^{-1}$ current density. The detailed electrochemical data are presented in Table 1. The ZnS composite delivered a very high initial capacity of $\sim 1014 \mathrm{~mA} \mathrm{~h} \mathrm{~g}^{-1}$, but the capacity sharply decreased to $\sim 279 \mathrm{~mA} \mathrm{~h} \mathrm{~g}^{-1}$ after 200 cycles, which is significantly lower than its theoretical value $\left(829 \mathrm{~mA} \mathrm{~h} \mathrm{~g}^{-1}\right)$ [44]. This is ascribed to the high volume change of active $\mathrm{ZnS}$ particles, which were pulverized and delaminated during the cycling. The ZnS-C electrode exhibited a slightly higher reversible capacity and better capacity retention (318 $\mathrm{mA} \mathrm{h} \mathrm{g}^{-1}$ after 200 cycles), mainly owing to the $\mathrm{C}$ matrix surrounding the nanosized $\mathrm{ZnS}$, which stabilized the lithiation/delithiation processes. The ZnS-TiC-C nanocomposite electrode exhibited excellent cyclic stability, delivering a highly stable reversible capacity of $\sim 613 \mathrm{~mA} \mathrm{~h} \mathrm{~g}^{-1}$ over 600 cycles, corresponding to a capacity retention of $\sim 77 \%$, which was significantly higher than that of ZnS-C ( $\sim 50 \%)$ and $\mathrm{ZnS}(\sim 44 \%)$. This superior cyclic performance is attributed to the introduction of the TiC-C phase into the ZnS alloy, which not only increased the conductivity of the composite, but also acted as a reinforcing matrix that mitigated the volume changes and suppressed the aggregation of the $\mathrm{ZnS}$ active material upon extended cycling, significantly enhancing the cycling stability of the ZnS-TiC-C nanocomposite [29,32]. The optimum active $\mathrm{ZnS}$ content in the composite was determined by measuring the cyclic performance of various ZnS-TiC-C composite electrodes at $0.1 \mathrm{~A} \mathrm{~g}^{-1}$ (Figure S1). Interestingly, all the ZnS-TiC-C composite electrodes exhibited excellent cycling stability over 600 cycles when the ZnS content was varied from $60 \%$ to $90 \%$. Among the investigated ZnS-TiC-C nanocomposite electrodes, $\mathrm{ZnS}(80 \%)$-TiC-C exhibited the best performance, delivering a very stable reversible capacity of $\sim 613 \mathrm{mAh} \mathrm{g}^{-1}$ after 600 cycles, 
with the corresponding stable Coulombic efficiency (CE) of $\sim 99 \%$. The long-term cyclic performance of the ZnS, ZnS-C, and ZnS-TiC-C electrodes were further measured at $1 \mathrm{~A} \mathrm{~g}^{-1}$ (Figure 6b). The ZnS-TiC-C electrode exhibited the best performance, delivering a significantly higher capacity $\left(\sim 467 \mathrm{~mA} \mathrm{~h}^{-1}\right)$ after 600 cycles than the ZnS-C and ZnS electrodes ( 297 and $\sim 179 \mathrm{~mA} \mathrm{~h} \mathrm{~g}^{-1}$, respectively).

(a)

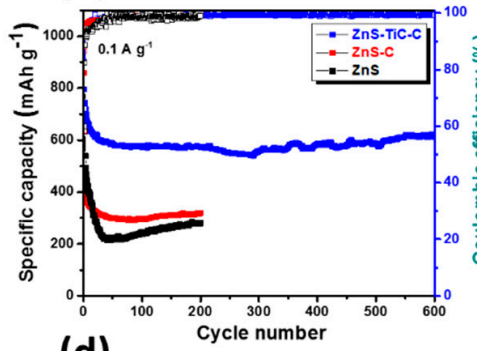

(d)

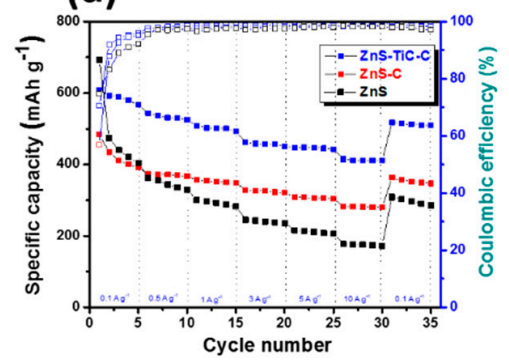

(b)

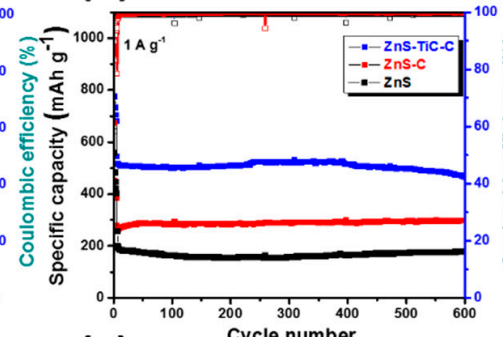

(e)

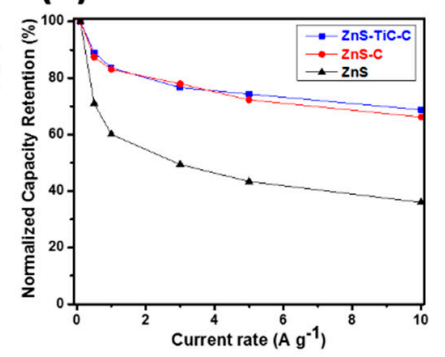

(c)

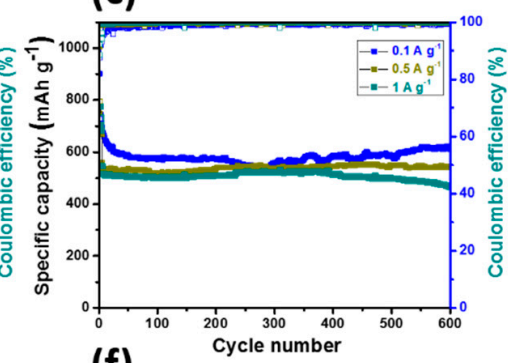

(f)

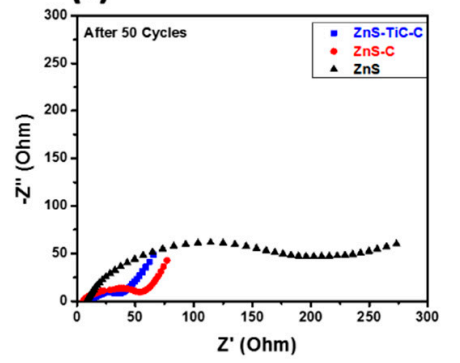

Figure 6. (a) Cyclic performance of the $\mathrm{ZnS}, \mathrm{ZnS}-\mathrm{C}$, and $\mathrm{ZnS}-\mathrm{TiC}-\mathrm{C}$ electrodes at $0.1 \mathrm{~A} \mathrm{~g}^{-1}$; (b) long-term cyclic performance of the $\mathrm{ZnS}, \mathrm{ZnS}-\mathrm{C}$, and $\mathrm{ZnS}-\mathrm{TiC}-\mathrm{C}$ electrodes at $1 \mathrm{~A} \mathrm{~g}^{-1}$; (c) comparison of the long-term cyclic performance of the ZnS-TiC-C electrodes at $0.1,0.5$, and $1 \mathrm{~A} \mathrm{~g}^{-1}$; (d) rate capability of the ZnS, ZnS-C, and ZnS-TiC-C electrodes; (e) normalized capacity retention of the ZnS, $\mathrm{ZnS}-\mathrm{C}$, and $\mathrm{ZnS}-\mathrm{TiC}-\mathrm{C}$ electrodes at different current densities ranging from 0.1 to $10 \mathrm{~A} \mathrm{~g}^{-1}$; and (f) electrochemical impedance spectra of the ZnS, ZnS-C, and ZnS-TiC-C electrodes after 50 cycles.

Table 1. Electrochemical data for the ZnS-based electrodes.

\begin{tabular}{|c|c|c|c|c|}
\hline Electrode & $\begin{array}{c}\text { 1st Discharge } \\
\text { Capacity }\left(\mathrm{mA} \mathrm{h} \mathrm{g}^{-1}\right)\end{array}$ & $\begin{array}{l}\text { 1st Charge Capacity } \\
\left(\mathrm{mA} \mathrm{h} \mathrm{g}^{-1}\right)\end{array}$ & $\begin{array}{l}\text { 1st Coulombic } \\
\text { Efficiency (\%) }\end{array}$ & $\begin{array}{c}\text { Capacity Retention } \\
(\%)(n t h / 2 n d \\
\text { Discharge Capacity) }\end{array}$ \\
\hline ZnS-TiC-C & 903 & 594 & 65.8 & $77.2(n=600)$ \\
\hline ZnS-C & 859 & 501 & 58.3 & $49.4(n=200)$ \\
\hline $\mathrm{ZnS}$ & 1014 & 609 & 60.1 & $44.0(n=200)$ \\
\hline
\end{tabular}

As shown in Figure 6c, although a capacity drop was observed relative to the specific capacity at $0.1 \mathrm{~A} \mathrm{~g}^{-1}$, the cyclic performance of the $\mathrm{ZnS}(80 \%)$-TiC-C electrode at the high current densities of $0.5 \mathrm{~A} \mathrm{~g}^{-1}$ and $1 \mathrm{~A} \mathrm{~g}^{-1}$ were very stable: the electrode delivered reversible capacities of $\sim 545 \mathrm{~mA} \mathrm{~h} \mathrm{~g}^{-1}$ at $0.5 \mathrm{~A} \mathrm{~g}^{-1}$ and $467 \mathrm{~mA} \mathrm{~h} \mathrm{~g}^{-1}$ at $1 \mathrm{~A} \mathrm{~g}^{-1}$ after 600 cycles. The rate capabilities of the ZnS-based electrodes at various current densities in the range of $0.1-10 \mathrm{~A} \mathrm{~g}^{-1}$ were measured and compared, as shown in Figure 6d. Similar to the case of the cyclic performance at $0.1 \mathrm{~A} \mathrm{~g}^{-1}$, among the ZnS-based composite electrodes, the $\mathrm{ZnS}(80 \%)$-TiC-C nanocomposite exhibited the highest average capacity at all current densities. Specifically, it delivered capacities of $\sim 599,533,501,457,439$, and $412 \mathrm{~mA} \mathrm{~h} \mathrm{~g}^{-1}$, respectively, at $0.1,0.5,1,3,5$, and $10 \mathrm{~A} \mathrm{~g}^{-1}$ with the corresponding capacity retentions of $100 \%$, $89 \%, 84 \%, 76 \%, 73 \%$, and $69 \%$ (relative to the initial capacity measured at $0.1 \mathrm{~A} \mathrm{~g}^{-1}$ ). In comparison, the ZnS-C and ZnS electrodes exhibited poorer rate capabilities. At the high current density of $10 \mathrm{~A} \mathrm{~g}^{-1}$, they delivered low specific capacities of $\sim 281$ and $175 \mathrm{~mA} \mathrm{~h} \mathrm{~g}^{-1}$ with the corresponding capacity retentions of $66 \%$ and $36 \%$, respectively. Furthermore, when the electrodes were returned to its original value of $0.1 \mathrm{~A} \mathrm{~g}^{-1}$, the capacity-retention values were $86 \%, 83 \%$, and $61 \%$ for the $\mathrm{ZnS}-\mathrm{TiC}-\mathrm{C}$, 
$\mathrm{ZnS}-\mathrm{C}$, and $\mathrm{ZnS}$ electrodes, respectively, suggesting the superior rate performance of the ZnS-TiC-C nanocomposite. The normalized capacity retentions in Figure 6e confirm the relatively high capacity retention of the $\mathrm{ZnS}-\mathrm{TiC}-\mathrm{C}$ electrode compared with the $\mathrm{ZnS}$ and $\mathrm{ZnS}-\mathrm{C}$ electrodes. This excellent performance indicates that the introduction of the TiC-C hybrid matrix facilitated $\mathrm{Li}^{+}$-ion transport between the active $\mathrm{ZnS}$ particles and mitigated the agglomeration and pulverization of the electrode during prolonged cycling [28-33]. Figure 6f shows Nyquist plots for the electrodes after 50 cycles. The detailed data for the charge-transfer resistance $\left(R_{c t}\right)$ and the SEI layer resistance $\left(R_{s}\right)$ are presented in Table S2. Among the electrodes, ZnS-TiC-C exhibited the best performance, as evidenced by the smallest semicircle and the lowest value of $\mathrm{R}_{\mathrm{ct}}$ after 50 cycles. In order to investigate the stability of a thin SEI layer during cycling, the EIS measurements were conducted at the fully discharged states of ZnS-TiC-C electrodes for the 1st, 2nd, and 7th cycle. The EIS spectra at the fully discharged state for the 1st cycle is typically different from the ones after the 2 nd and 7th cycles, which is consistent with the $\mathrm{CV}$ results (Figure 4d). In particular, two semicircles were observed in the EIS spectra after being fully discharged, corresponding to the SEI layer resistance $\left(R_{S}\right)$ for the first semicircle and the charge-transfer resistance $\left(R_{c t}\right)$ for the second semicircle. As seen in Figure $S 2$, the EIS spectra of the 2nd and 7th cycles show the similar shape and size for the first semicircle, indicating the resistance of the SEI layer $\left(R_{s}\right)$ was nearly unchanged during cycling. These results indicate that the introduction of the TiC-C hybrid matrix to active $\mathrm{ZnS}$ anode provides effective electron pathways and maintains a stable SEI layer during cycling, thereby improving the interfacial stability and electronic conductivity of the composite. The sheet resistance measurements were further conducted using 4-point probe method (CMT-SR1000 $\mathrm{N})$ to confirm the high conductivity of the ZnS-TiC-C nanocomposite. The slurries of ZnS, ZnS-C, and $\mathrm{ZnS}-\mathrm{TiC}-\mathrm{C}$ were first cast on the $\mathrm{Si}$ wafer with the thickness of $30 \mu \mathrm{m}$. The sheet resistances $\left(\mathrm{R}_{\mathrm{sh}}\right)$ of the ZnS-TiC-C, ZnS-C, and ZnS were measured to be $294 \pm 3,346 \pm 8$, and $522 \pm 46 \Omega /$ sq, respectively. This corresponds to the conductivities $\left(\sigma=1 /\left(\mathrm{R}_{\mathrm{sh}} \times \mathrm{t}\right)\right)$ of $113 \pm 1,96 \pm 2$, and $64 \pm 6 \mathrm{~S} / \mathrm{cm}$, indicating the highest conductivity of ZnS-TiC-C, followed by ZnS-C and ZnS, as shown in Figure S3.

The morphologies of the ZnS-TiC-C and ZnS-C electrodes were observed after 50 charge/discharge cycles using ex-situ SEM (Figure 7). The ZnS-C electrode film was partly peeled off from the current collector and exhibited a poor morphology, with significant aggregation, pulverization, and cracks (Figure $7 \mathrm{~b}, \mathrm{~d}$ ). In contrast, the $\mathrm{ZnS}$-TiC-C electrode exhibited better morphology without any aggregations, delamination or cracks (Figure $7 \mathrm{a}, \mathrm{c}$ ). This result can explain the superior electrochemical performance of ZnS-TiC-C.

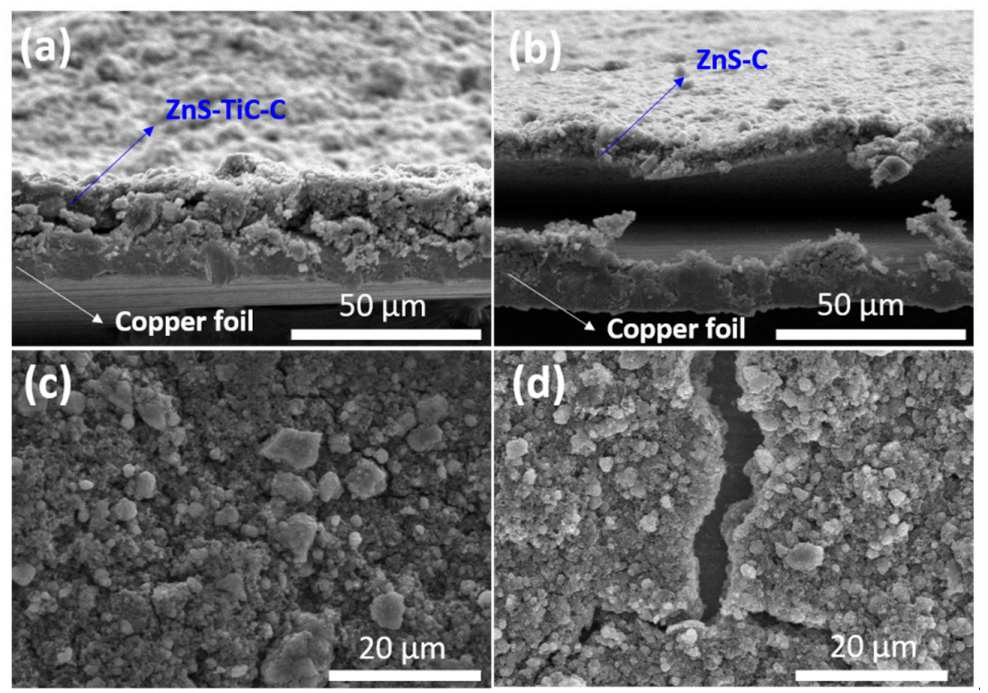

Figure 7. Ex situ SEM images of the (a,c) ZnS-TiC-C and (b,d) ZnS-C electrodes after 50 cycles at $0.1 \mathrm{~A} \mathrm{~g}^{-1}$.

To demonstrate the feasibility of the ZnS-TiC-C composite for practical energy-storage applications, LIB full-cell investigations were performed using the ZnS-TiC-C as an anode and the synthesized 
$\mathrm{LiFePO}_{4}$-graphite (LFG-G) as a cathode, as shown in Figure 8. Considering the specific capacity balance, the mass ratio of the cathode to the anode was $\sim 2: 1$. Figure 8a presents the charge/discharge profiles of the ZnS-TiCC//LFP-G full-cell at $0.1 \mathrm{~A} \mathrm{~g}^{-1}$ in the range of 1.0-3.8 $\mathrm{V}$. A nominal cell voltage at $\sim 2.5 \mathrm{~V}$ was observed during the charge/discharge process, resulting from the distinct reaction potentials between $\mathrm{LiFePO}_{4}$ and $\mathrm{ZnS}$. As shown in Figure 8b, the ZnS-TiC-C//LFP-G full cell exhibited a highly stable lifecycle without remarkable capacity fading at $0.1 \mathrm{~A} \mathrm{~g}^{-1}$, delivering a specific capacity of $\sim 71 \mathrm{~mA}$ $\mathrm{h} \mathrm{g}^{-1}$ (calculated using the total mass of the anode and cathode) even after 200 cycles. The full cell exhibited reversible capacities of $\sim 95,70,59$, and $45 \mathrm{~mA} \mathrm{~h} \mathrm{~g}^{-1}$, respectively, at $0.1,0.5,1$, and $3 \mathrm{~A} \mathrm{~g}^{-1}$ (Figure $8 \mathrm{c}$ ). Although the capacity gradually decreased with the increasing current rate, it recovered to $\sim 81 \mathrm{~mA} \mathrm{~h} \mathrm{~g}{ }^{-1}$ (corresponding capacity retention of $\sim 86 \%$ ) when the current density was turned back to its original value of $0.1 \mathrm{~A} \mathrm{~g}^{-1}$. Furthermore, the duration of the capacity at each current density was excellent, indicating the good rate performance of the ZnS-TiC-C nanocomposite as an anode for full-cell applications. The practical energy densities of the ZnS-TiC-C//LFP-G full cell at different current rates were calculated using the working potential $(\sim 2.5 \mathrm{~V})$ and the capacity from rate-capability measurements (Figure 8d). The calculated energy densities of the ZnS-TiC-C//LFP-G full cell were $236,175,148$, and $112 \mathrm{Wh} \mathrm{kg}^{-1}$, respectively, at $0.1,0.5,1$, and $3 \mathrm{~A} \mathrm{~g}^{-1}$ which were significantly higher than the energy densities of the common full cell using $\mathrm{Li}_{4} \mathrm{Ti}_{5} \mathrm{O}_{12}$ as an anode and LFP as a cathode $\left(\sim 140 \mathrm{Wh} \mathrm{kg}^{-1}\right.$ at $\left.0.1 \mathrm{~A} \mathrm{~g}^{-1}\right)$ [52].

(a)

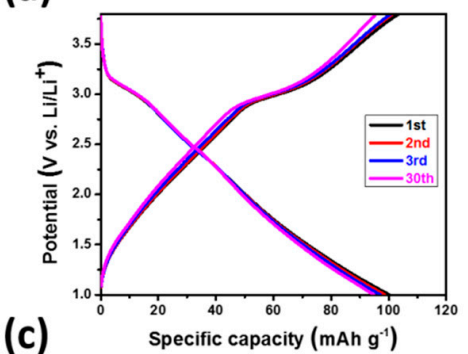

(c)

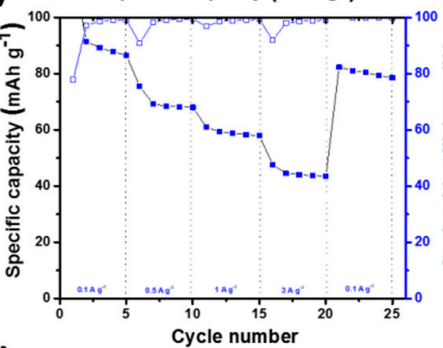

(b)

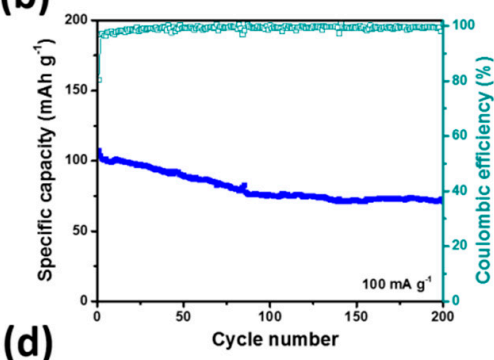

(d)

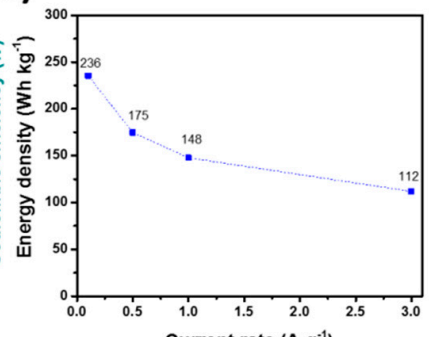

Current rate $\left(\mathrm{A} \mathrm{g}^{-1}\right)$

\section{(e)}

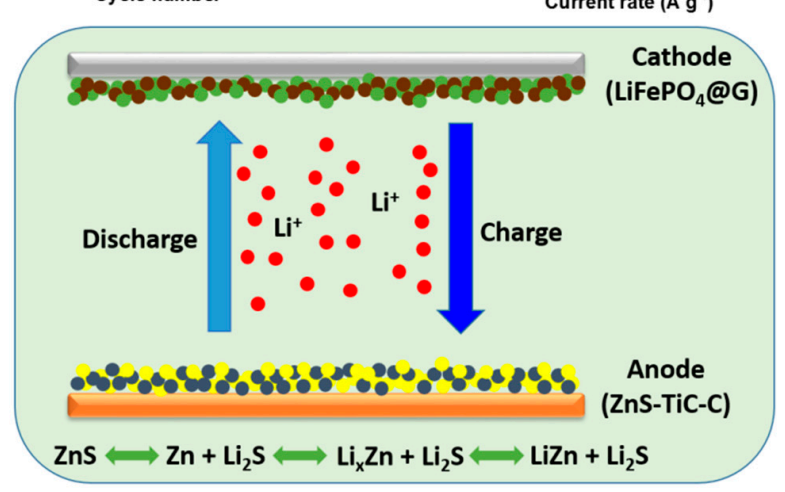

Figure 8. Performance of the full cell using $\mathrm{ZnS}(80 \%)-\mathrm{TiC}-\mathrm{C}$ as an anode and $\mathrm{LiFePO}_{4}-\mathrm{G}$ as a cathode: (a) galvanostatic charge/discharge profiles obtained at $0.1 \mathrm{~A} \mathrm{~g}^{-1}$ over the voltage range of 1-3.8 V; (b) cyclic performance at $0.1 \mathrm{~A} \mathrm{~g}^{-1}$; (c) rate capability at different current densities ranging from 0.1 to $3 \mathrm{~A} \mathrm{~g}^{-1}$; (d) energy density at different current rates of the ZnS-TiC-C//LFP-G full cell; and (e) schematic of the $\mathrm{ZnS}-\mathrm{TiC}-\mathrm{C} / / \mathrm{LFP}-\mathrm{G}$ full cell. 


\section{Conclusions}

We synthesized a ZnS-TiC-C nanocomposite using a facile, low-cost, and eco-friendly HEBM process, for use as an anode material in LIBs. Structural and morphological characterizations revealed that $\mathrm{ZnS}$ nanocrystallites were uniformly dispersed in a multifunctional TiC-C hybrid matrix, resulting in superior electrochemical performance (i.e., stable reversible capacity, exceptional cyclability, and good rate capability) compared with $\mathrm{ZnS}-\mathrm{C}$ and $\mathrm{ZnS}$ composites. The electrochemical performance was remarkably improved by the introduction of $\mathrm{TiC}$ to the $\mathrm{ZnS}-\mathrm{C}$ composites, because the TiC-C buffering matrix offers high electronic conductivity to the active $\mathrm{ZnS}$ particles and prevents the high volume change during prolonged cycling. The ZnS-TiC-C electrode delivered a highly reversible capacity (613 $\mathrm{mA} \mathrm{h} \mathrm{g}^{-1}$ over 600 cycles, corresponding to $77 \%$ capacity retention) and good rate performance, with $\sim 69 \%$ capacity retention at a high current density of $10 \mathrm{~A} \mathrm{~g}^{-1}$. Moreover, the $\mathrm{ZnS}-\mathrm{TiC}-\mathrm{C}$ electrode exhibited very stable long-term cyclic performance even at high current densities $\left(\sim 545 \mathrm{~mA} \mathrm{~h} \mathrm{~g}^{-1}\right.$ at 0.5 at $0.5 \mathrm{~A} \mathrm{~g}^{-1}$ and $407 \mathrm{~mA} \mathrm{~h} \mathrm{~g}^{-1}$ and $1.0 \mathrm{~A} \mathrm{~g}^{-1}$, respectively, after 600 cycles). Furthermore, a full cell consisting of an LFP-G cathode and a ZnS-TiC-C anode exhibited very stable cyclic performance without a significant capacity reduction, delivering a specific capacity of $71 \mathrm{~mA} \mathrm{~h} \mathrm{~g}^{-1}$ after 200 cycles. Thus, the ZnS-TiC-C nanocomposite can be a potential candidate for high-performance LIB anodes.

Supplementary Materials: The following are available online at http://www.mdpi.com/2079-4991/9/9/1221/s1, Figure S1: Cyclic performance of various ZnS-TiC-C electrodes at $0.1 \mathrm{~A} \mathrm{~g}^{-1}$, Figure S2: EIS spectra of ZnS-TiC-C electrodes fully discharged states for 1st, 2nd, and 7th cycle, Figure S3: Conductivities of ZnS-TiC-C, ZnS-C, and ZnS, Table S1: ZnS-based anode materials for LIBs, Table S2. EIS data for ZnS-based electrodes after 50 cycles.

Author Contributions: Investigation and writing-original draft preparation, Q.H.N.; supervision and writing-review and editing, J.H.

Funding: This work was supported by the Korea Institute of Energy Technology Evaluation and Planning (KETEP) and the Ministry of Trade, Industry and Energy (MOTIE) of the Republic of Korea (No. 20194030202290). It was also supported by the Nano Material Technology Development Program through the National Research Foundation of Korea (NRF) funded by the Ministry of Science, ICT and Future Planning (2009-0082580). We thank the Smart Materials Research Center for IoT at Gachon University for its instrumental support (XRD and SEM).

Conflicts of Interest: The authors declare no conflict of interest.

\section{References}

1. Ji, L.; Lin, Z.; Alcoutlabi, M.; Zhang, X. Recent developments in nanostructured anode materials for rechargeable lithium-ion batteries. Energy Environ. Sci. 2011, 4, 2682-2699. [CrossRef]

2. Etacheri, V.; Marom, R.; Elazari, R.; Salitra, G.; Aurbach, D. Challenges in the development of advanced Li-ion batteries: A review. Energy. Environ. Sci. 2011, 4, 3243-3262. [CrossRef]

3. Yim, C.H.; Courtel, F.M.; Abu-Lebdeh, Y. A high capacity silicon-graphite composite as anode for lithium-ion batteries using low content amorphous silicon and compatible binders. J. Mater. Chem. A 2013, 1, 8234-8243. [CrossRef]

4. Goriparti, S.; Miele, E.; De Angelis, F.; Di Fabrizio, E.; Zaccaria, R.P.; Capiglia, C. Review on recent progress of nanostructured anode materials for Li-ion batteries. J. Power Sources 2014, 257, 421-443. [CrossRef]

5. Zhang, W.J. A review of the electrochemical performance of alloy anodes for lithium-ion batteries. J. Power Sources 2011, 196, 13-24. [CrossRef]

6. Lu, L.; Han, X.; Li, J.; Hua, J.; Ouyang, M. A review on the key issues for lithium-ion battery management in electric vehicles. J. Power Sources 2013, 226, 272-288. [CrossRef]

7. Doh, C.H.; Jin, B.S.; Lim, J.H.; Moon, S.I. Electrochemical characteristics of lithium transition-metal oxide as an anode material in a lithium secondary battery. Korean J. Chem. Eng. 2002, 19, 749-755. [CrossRef]

8. Jeong, J.H.; Jung, D.W.; Kong, B.S.; Shin, C.M.; Oh, E.S. The effect of graphene nanosheets as an additive for anode materials in lithium ion batteries. Korean J. Chem. Eng. 2011, 28, 2202-2205. [CrossRef]

9. Hai, N.Q.; Kim, H.; Yoo, I.S.; Kim, J.H.; Hur, J. Comparative study of mechanically milled $\mathrm{MoS}_{2}$ and $\mathrm{MoSe}_{2}$ in graphite matrix as anode materials for high-performance lithium-ion batteries. J. Nanosci. Nanotechnol. 2018, 18, 6469-6474. [CrossRef] 


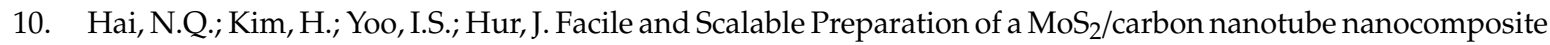
anode for high-performance lithium-ion batteries: effects of carbon nanotube content. J. Nanosci. Nanotechnol. 2019, 19, 1494-1499. [CrossRef]

11. Nguyen, Q.H.; Choi, J.S.; Lee, Y.C.; Kim, I.T.; Hur, J. 3D hierarchical structure of MoS $@$ G-CNT combined with post-film annealing for enhanced lithium-ion storage. J. Ind. Eng. Chem. 2019, 69, 116-126. [CrossRef]

12. Obrovac, M.; Chevrier, V. Alloy negative electrodes for Li-ion batteries. Chem. Rev. 2014, 11, 11444-11502. [CrossRef] [PubMed]

13. Nguyen, Q.H.; Hung, N.T.; Park, S.J.; Kim, I.T.; Hur, J. Enhanced performance of carbon-free intermetallic zinc titanium alloy $\left(\mathrm{Zn}-\mathrm{Zn}_{\mathrm{x}} \mathrm{Ti}_{\mathrm{y}}\right.$ ) anode for lithium-ion batteries. Electrochim. Acta 2019, 301, 229-239. [CrossRef]

14. Hai, N.Q.; Kwon, S.H.; Kim, H.; Kim, I.T.; Lee, S.G.; Hur, J. High-performance $\mathrm{MoS}_{2}$-based nanocomposite anode prepared by high-energy mechanical milling: The effect of carbonaceous matrix on $\mathrm{MoS}_{2}$. Electrochim. Acta 2018, 260, 129-138. [CrossRef]

15. Hung, N.T.; Bae, J.; Kim, J.H.; Son, H.B.; Kim, I.T.; Hur, J. Facile preparation of a zinc-based alloy composite as a novel anode material for rechargeable lithium-ion batteries. Appl. Surf. Sci. 2018, 429, 210-217. [CrossRef]

16. Park, C.M.; Kim, J.H.; Kim, H.; Sohn, H.J. Li-alloy based anode materials for Li secondary batteries. Chem. Soc. Rev. 2010, 39, 3115-3141. [CrossRef] [PubMed]

17. He, L.; Liao, X.Z.; Yang, K.; He, Y.S.; Wen, W.; Ma, Z.F. Electrochemical characteristics and intercalation mechanism of $\mathrm{ZnS} / \mathrm{C}$ composite as anode active material for lithium-ion batteries. Electrochim. Acta 2011, 56, 1213-1218. [CrossRef]

18. Park, A.R.; Jeon, K.J.; Park, C.M. Electrochemical mechanism of Li insertion/extraction in ZnS and ZnS/C anodes for Li-ion batteries. Electrochim. Acta 2018, 265, 107-114. [CrossRef]

19. Saadat, S.; Tay, Y.Y.; Zhu, J.; Teh, P.F.; Maleksaeedi, S.; Shahjamali, M.M.; Shakerzadeh, M.; Srinivasan, M.; Tay, B.Y.; Hng, H.H. Template-free electrochemical deposition of interconnected ZnSb nanoflakes for li-ion battery anodes. Chem. Mater. 2011, 23, 1032-1038. [CrossRef]

20. Park, C.M.; Sohn, H.J. Quasi-Intercalation and facile amorphization in layered ZnSb for Li-ion batteries. Adv. Mater. 2010, 22, 47-52. [CrossRef]

21. Park, M.G.; Lee, C.K.; Park, C.M. Amorphized ZnSb-based composite anodes for high-performance Li-ion batteries. RSC Adv. 2014, 4, 5830-5833. [CrossRef]

22. Hwa, Y.; Sung, J.H.; Wang, B.; Park, C.M.; Sohn, H.J. Nanostructured Zn-based composite anodes for rechargeable Li-ion batteries. J. Mater. Chem. 2012, 22, 12767-12773. [CrossRef]

23. Seo, J.U.; Park, C.M. ZnTe and ZnTe/C nanocomposite: A new electrode material for high-performance rechargeable Li-ion batteries. J. Mater. Chem. A 2014, 2, 20075-20082. [CrossRef]

24. Kwon, H.T.; Park, C.M. Electrochemical characteristics of ZnSe and its nanostructured composite for rechargeable Li-ion batteries. J. Power Sources 2014, 251, 319-324. [CrossRef]

25. Zhang, Z.; Fu, Y.; Yang, X.; Qu, Y.; Li, Q. Nanostructured ZnSe anchored on graphene nanosheets with superior electrochemical properties for lithium ion batteries. Electrochim. Acta 2015, 168, 285-291. [CrossRef]

26. Besenhard, J.; Hess, M.; Komenda, P. Dimensionally stable Li-alloy electrodes for secondary batteries. Solid State Ion. 1990, 40, 525-529. [CrossRef]

27. Wang, L.; Zhang, G.; Liu, Q.; Duan, H. Recent progress in Zn-based anodes for advanced lithium ion batterie. Mater. Chem. Front. 2018, 2, 1414-1435. [CrossRef]

28. Leibowitz, J.; Allcorn, E.; Manthiram, A. SnSb-TiC-C nanocomposite alloy anodes for lithium-ion batteries. J. Power Sources 2015, 279, 549-554. [CrossRef]

29. Son, S.Y.; Hur, J.; Kim, K.H.; Son, H.B.; Lee, S.G.; Kim, I.T. SnTe-TiC-C composites as high-performance anodes for Li-ion batteries. J. Power Sources 2017, 365, 372-379. [CrossRef]

30. Kim, I.T.; Kim, S.O.; Manthiram, A. Effect of TiC addition on SnSb-C composite anodes for sodium-ion batteries. J. Power Sources 2014, 269, 848-854. [CrossRef]

31. Allcorn, E.; Manthiram, A. High-rate, high-density FeSb-TiC-C nanocomposite anodes for lithium-ion batteries. J. Mater. Chem. A 2015, 3, 3891-3900. [CrossRef]

32. Kim, H.; Kim, M.; Yoon, Y.H.; Nguyen, Q.H.; Kim, I.T.; Hur, J.; Lee, S.G. Sb $2 \mathrm{Te}_{3}-\mathrm{TiC}-\mathrm{C}$ nanocomposites for the high-performance anode in lithium-ion batteries. Electrochim. Acta 2019, 293, 8-18. [CrossRef]

33. Kim, S.O.; Manthiram, A. High-Performance Zn-TiC-C Nanocomposite Alloy Anode with Exceptional Cycle Life for Lithium-Ion Batteries. ACS Appl. Mater. Interfaces 2015, 7, 14801-14807. [CrossRef] [PubMed] 
34. Applestone, D.; Manthiram, A. $\mathrm{Cu}_{6} \mathrm{Sn}_{5}-\mathrm{TiC}-\mathrm{C}$ nanocomposite alloy anodes with high volumetric capacity for lithium ion batteries. RSC Adv. 2012, 2, 5411-5417. [CrossRef]

35. Nguyen, Q.H.; Hur, J. MoS 2 -TiC-C Nanocomposites as New Anode Materials for High-Performance Lithium-Ion Batteries. J. Nanosci. Nanotechnol. 2019, 19, 996-1000. [CrossRef] [PubMed]

36. Jia, H.; Zhang, Z.; Qi, Z.; Liu, G.; Bian, X. Formation of nanocrystalline TiC from titanium and different carbon sources by mechanical alloying. J. Alloys Compd. 2009, 472, 97-103. [CrossRef]

37. Mani, A.; Aubert, P.; Mercier, F.; Khodja, H.; Berthier, C.; Houdy, P. Effects of residual stress on the mechanical and structural properties of TiC thin films grown by RF sputtering. Surf. Coat. Technol. 2005, 194, 190-195. [CrossRef]

38. Zhang, K.; Xu, Y.; Lu, Y.; Zhu, Y.; Qian, Y.; Wang, D.; Zhou, J.; Lin, N.; Qian, Y. A graphene oxide-wrapped bipyramidal sulfur@ polyaniline core-shell structure as a cathode for Li-S batteries with enhanced electrochemical performance. J. Mater. Chem. A 2016, 4, 6404-6410. [CrossRef]

39. Zhang, S.; Ueno, K.; Dokko, K.; Watanabe, M. Recent Advances in Electrolytes for Lithium-Sulfur Batteries. Adv. Energy Mater. 2015, 5, 1500117. [CrossRef]

40. Manthiram, A.; Fu, Y.; Chung, S.H.; Zu, C.; Su, Y.S. Rechargeable lithium-sulfur batteries. Chem. Rev. 2014, 114, 11751-11787. [CrossRef]

41. Barghamadi, M.; Kapoor, A.; Wen, C. A review on Li-S batteries as a high efficiency rechargeable lithium battery. J. Electrochem. Soc. 2013, 160, A1256-A1263. [CrossRef]

42. Du, X.; Zhao, H.; Zhang, Z.; Lu, Y.; Gao, C.; Li, Z.; Teng, Y.; Zhao, L.; Świerczek, K. Synthesis of core-shell-like $\mathrm{ZnS} / \mathrm{C}$ nanocomposite as improved anode material for lithium ion batteries. Electrochim. Acta 2017, 225, 129-136. [CrossRef]

43. Du, X.; Zhao, H.; Lu, Y.; Zhang, Z.; Kulka, A.; Świerczek, K. Core-shell structured ZnS-C nanoparticles with enhanced electrochemical properties for high-performance lithium-ion battery anodes. Electrochim. Acta 2017, 228, 100-106. [CrossRef]

44. Chen, H.; Zhang, B.; Cao, Y.; Wang, X.; Yao, Y.; Yu, W.; Zheng, J.; Zhang, J.; Tong, H. ZnS nanoparticles embedded in porous honeycomb-like carbon nanosheets as high performance anode material for lithium ion batteries. Ceram. Int. 2018, 44, 13706-13711. [CrossRef]

45. Wang, L.; Ju, J.; Deng, N.; Wang, G.; Cheng, B.; Kang, W. ZnS nanoparticles anchored on porous carbon nanofibers as anode materials for lithium ion batteries. Electrochem. Commun. 2018, 96, 1-5. [CrossRef]

46. Qin, W.; Li, D.; Zhang, X.; Yan, D.; Hu, B.; Pan, L. ZnS nanoparticles embedded in reduced graphene oxide as high performance anode material of sodium-ion batteries. Electrochim. Acta 2016, 191, 435-443. [CrossRef]

47. Fu, Y.; Zhang, Z.; Yang, X.; Gan, Y.; Chen, W. ZnS nanoparticles embedded in porous carbon matrices as anode materials for lithium ion batteries. RSC Adv. 2015, 5, 86941-86944. [CrossRef]

48. Li, J.; Yan, D.; Zhang, X.; Hou, S.; Lu, T.; Yao, Y.; Pan, L. ZnS nanoparticles decorated on nitrogen-doped porous carbon polyhedra: A promising anode material for lithium-ion and sodium-ion batteries. J. Mater. Chem. A 2017, 5, 20428-20438. [CrossRef]

49. Li, J.; Fu, Y.; Shi, X.; Xu, Z.; Zhang, Z. Urchinlike ZnS Microspheres decorated with nitrogen-doped carbon: a superior anode material for lithium and sodium Storage. Chem. Eur. J. 2017, 23, 157-166. [CrossRef]

50. Manthiram, A. Materials challenges and opportunities of lithium ion batteries. J. Phys. Chem. Lett. 2011, 2, 176-184. [CrossRef]

51. Goodenough, J.B.; Kim, Y. Challenges for rechargeable Li batteries. Chem. Mater. 2009, 22, 587-603. [CrossRef]

52. Qin, M.; Li, Y.; Lv, X.J. Preparation of Ce-and La-doped $\mathrm{Li}_{4} \mathrm{Ti}_{5} \mathrm{O}_{12}$ nanosheets and their electrochemical performance in $\mathrm{Li}$ half cell and $\mathrm{Li}_{4} \mathrm{Ti}_{5} \mathrm{O}_{12} / \mathrm{LiFePO}_{4}$ full cell batteries. Nanomaterials 2017, 7, 150. [CrossRef] [PubMed]

(C) 2019 by the authors. Licensee MDPI, Basel, Switzerland. This article is an open access article distributed under the terms and conditions of the Creative Commons Attribution (CC BY) license (http://creativecommons.org/licenses/by/4.0/). 